\title{
Educação permanente em Saúde e Metodologias Ativas de ensino: uma revisão sistemática integrativa
}

\author{
Permanent education in Health and Active Learning methodologies: a systematic integrative review
} Educación permanente en Salud y Metodologías Activas de enseñanza: una revisión de sistemática integradora

Renata Jacobovski

ORCID: https://orcid.org/0000-0001-6028-5528 Universidade Federal do Paraná, Brasil E-mail: renatajacobovski@gmail.com

Luis Felipe Ferro

ORCID: https://orcid.org/0000-0001-8935-104X Universidade Federal do Paraná, Brasil E-mail: luisfelipeferro@gmail.com

\begin{abstract}
Resumo
A Política Nacional de Educação Permanente em Saúde (EPS) regulamentou a formação de recursos humanos para o SUS, apresentando entre suas diretrizes a adoção de metodologias ativas (MAs) para promover aprendizagens significativas e críticas. O presente estudo, pautado na revisão sistemática integrativa, teve como objetivo aprofundar e sistematizar conhecimentos sobre a utilização de estratégias de MAs em processos de EPS. A busca de literatura envolveu as bases de dados da Biblioteca Virtual em Saúde e obteve 18 trabalhos. Para a análise dos dados, foi utilizada a Matriz de Síntese, possibilitando a categorização em núcleos temáticos. Observa-se que todos os trabalhos apresentaram princípios acerca das MAs, afirmando sua potência como método alternativo ao modelo tradicional de ensino. Dentre as estratégias para a implementação das MAs em processos de EPS, foram destacados os trabalhos em grupos, equipes e ações em redes; a experimentação e problematização da realidade; os seminários, diálogos, dinâmicas e oficinas. No tocante às avaliações, ressalta-se a necessidade de práticas inclusivas e processuais. A bibliografia ainda destaca a importância da constituição de currículos integrados, que promovam coesão entre conhecimentos e alinhamento da teoria à prática, articulando ações entre formação na graduação e práticas de EPS. Para além, os trabalhos ressaltam a importância do uso das Tecnologias de Informação e Comunicação enquanto estratégia para proporcionar novas formas de aplicação da educação a distância e das MAs. Por fim, sugere-se estudos que delimitem com maior profundidade o conceito acerca das MAs, elucidando estratégias inovadoras que sejam aplicáveis, replicáveis e transformadoras da realidade.
\end{abstract}

Palavras-chave: Educação permanente em saúde; Metodologias ativas; Ensino; Políticas públicas.

\begin{abstract}
The National Policy for Permanent Education in Health (EPS) has structured the training of human resources for the Brazilian Unified Health System (SUS), presenting among its guidelines the adoption of active learning methodologies (MAs) to promote meaningful and critical education. This research, based on the systematic integrative review, aimed to deepen and systematize knowledge about the use of MAs strategies in EPS processes. The literature review involved the databases of the Virtual Health Library and obtained 18 papers. For data analysis, a synthesis matrix was used, in order to organize and categorize the information. We observed that all research focused on detailing the principles about MAs. Regarding the definitions, most of the works conceptualized MAs as an alternative method to the traditional teaching model. Among the implementation strategies, we list the work in groups, teams and actions in networks; the experimentation and problematization of reality; seminars, dialogues, dynamics and workshops. With regard to evaluations, the need for most inclusive and procedural practices is emphasized. In relation to integrated curricular guidelines, the importance of curricular bases that promote cohesion between knowledge and alignment of theory to practice is highlighted. Concerning the use of ICTs, we observed that this tool provides new ways of applying distance education and MAs. Finally, studies are suggested to delimit the concept of MAs with greater precision and depth, including innovative strategies that are applicable, replicable and transforming reality.
\end{abstract}

Keywords: Permanent education in health; Active learning methodologies; Teaching; Public policy. 


\begin{abstract}
Resumen
La Política Nacional de Educación Permanente en Salud (EPS) estructuró la formación de recursos humanos para el Sistema Único de Salud (SUS), presentando entre sus directrices la adopción de metodologías activas de enseñanza (MAs) para promover aprendizajes significativos y críticos. Este estudio, marcado por la revisión sistemática integradora de literatura, buscó profundizar y sistematizar los conocimientos sobre el uso de estrategias de MAs en los procesos de EPS. La búsqueda de literatura usó la base de datos de la Biblioteca Virtual de Salud obteniendo 18 trabajos. Para el análisis de datos se utilizó la matriz de síntesis, con el propósito de organizar y categorizar la información. Se observa que todos los trabajos tuvieron foco en detallar los principios de las MAs, y las definiciones apuntan a este como un método alternativo al modelo tradicional de enseñanza. Entre las estrategias de implementación, se destacan los trabajos grupales, las acciones en red, la experiencia y problematización de la realidad; exposiciones, diálogos, dinámicas y talleres. Sobre métodos de evaluación, se resalta la necesidad de prácticas más inclusivas y procedimentales. Sobre las directrices curriculares integradas, se destacan aquellas que promuevan cohesión entre los conocimientos y alineamiento de teoría y práctica. Respecto al uso de Tecnologías de Información y Comunicación, puede decirse que proporcionan nuevas formas de aplicación de la educación a distancia y MAs. Por último, son sugeridos estudios que profundicen el concepto de MAs con mayor precisión, proponiendo estrategias innovadoras que sean aplicables, replicables y transformadoras de la realidad.
\end{abstract}

Palabras clave: Educación permanente en salud; Metodologías activas; Ensenãnza; Políticas públicas.

\title{
1. Introdução
}

O modelo tradicional de ensino, muito utilizado na formação dos profissionais da saúde, baseia-se na educação passiva do aluno, centrando-se em aulas expositivas, presenciais e na reprodução e memorização de conteúdos. Nessa modalidade, o ensino é verticalizado, focado no docente, com viés pouco crítico e distante da participação ativa na realidade, divergindo, muitas vezes, das necessidades formativas do trabalhador da saúde. Dessa forma, no contexto da produção do cuidado, torna-se essencial aprender a lidar com diferentes processos individuais, familiares e comunitários, atuando diretamente nos determinantes sociais e na qualidade de vida das populações (Hermida, Barbosa \& Heidemann, 2015; Lázaro, Sato \& Tezani, 2018).

Por sua vez, destacando a necessidade de processos educativos constantes voltados a profissionais, o termo Educação Permanente (EP) foi cunhado na década de 1950 na França e difundido internacionalmente pela Organização das Nações Unidas para a Educação, a Ciência e a Cultura (UNESCO) a partir da década de 1960 (Lemos, 2016; Schultz, 1985). Neste contexto, a EP vem sendo construída como uma prática formativa contínua que propõe a reflexão sobre o trabalho e a aprendizagem no ambiente laboral, norteada por processos de aprendizagem coletivos, colaborativos e significativos, com compartilhamento de saberes, diálogos horizontais e participação social (Ministério da Saúde, 2018; Gonçalves, Pinto, França \& Teixeira, 2019; Souza \& Costa, 2019).

Nesse sentido, a Educação Permanente em Saúde (EPS) busca romper com o modelo tradicional de ensino ao propor a interação entre ensino, serviço e comunidade, afirmando a necessidade estratégica de aliar, de maneira transformadora, ações educativas aos processos de trabalho em saúde e de construir/fortalecer relações interprofissionais que impactem na realidade concreta dos territórios. E assim o faz mediante um ensino problematizador e crítico do cotidiano, pela produção de conhecimento no dia-a-dia do trabalho, pela construção de novas práticas assistenciais, soluções criativas e movimentos transformadores da realidade do cuidado (Gonçalves, Pinto, França \& Teixeira, 2019; Ministério da Saúde, 2018; De-Carli, Silva, Zafalon, Mitre, Pereira, Bomfim \& Theobald, 2019; França, Pierantoni, Belisario, Medeiros, Castro, Cardoso \& Garcia, 2016; Pinheiro, Azambuja \& Bonamigo, 2018; Souza \& Costa, 2019).

Para além de um método didático, a EPS deve ser compreendida como um processo político-pedagógico, a partir do qual os diferentes atores sociais envolvidos podem assumir mutuamente o compromisso de construir, de maneira indissociável e socialmente engajada, conhecimento e relações comunitárias que transformem realidades no sentido de promover a Saúde. Em contexto brasileiro, a promulgação da Lei 8.080/1990 estabeleceu as bases para a organização de um sistema de formação de recursos humanos na área da saúde, marco legal que proporcionou a edificação paulatina de práticas pautadas na EPS 
(Governo Federal, 1990; Ministério da Saúde, 2018; Ceccim \& Ferla, 2008).

A instituição da Política Nacional de Educação Permanente em Saúde (PNEPS), por sua vez, ocorreu por meio da Portaria no198/2004, atualmente em vigência pela Portaria de consolidação no2/2017. Em sua proposta, a PNEPS prevê a execução de ações educativas pautadas na realidade dos serviços que promovam transformações nos processos de trabalho e reflexões acerca da prática profissional. Além disso, a interação entre diferentes instituições comunitárias e atores sociais, proporcionando, por meio de metodologias ativas (MAs), aprendizagens significativas e críticas (Ministério da Saúde, 2004, 2014, 2017).

Nesse contexto, as MAs podem ser entendidas como estratégias didático-pedagógicas alternativas ao ensino tradicional, com diferentes formas de operacionalização e aplicáveis em variados cenários. Em sua proposta, as MAs preconizam a auto-aprendizagem mediante a curiosidade; a problematização da realidade pelo ato de fazer e refletir na prática, de acordo com o ritmo e perfil do próprio aluno; o estabelecimento de interações horizontais e o intercâmbio de conhecimentos entre as pessoas; a participação ativa e engajada do aprendiz em um processo educativo significativo para a compreensão e transformação dos cotidianos de vida (Bacich \& Moran, 2018; Freitas, Freitas, Parente, Vasconcelos, Lima, Mesquita \& Mendes, 2015; Valente, Almeida \& Geraldini, 2017).

Às MAs se torna imprescindível proporcionar, ainda, o envolvimento de todos os participantes em situações/problemas que mobilizem competências intelectuais, emocionais, comunicativas e relacionais para a composição e/ou execução coletiva de possibilidades de intervenção. Conforme Bacich e Moran (2018), tal processo se torna único e diferenciado para cada aluno, o qual participa, de maneira singular, pautado em toda uma trajetória de vida, da construção do conhecimento.

Enquanto proposta, diferentes autores apontam como alicerces das MAs: a educação centrada no aprendiz, tendo como foco um processo de ensino-aprendizagem crítico e reflexivo; a autonomia e pró-atividade do educando; a construção ativa do conhecimento, com ênfase dada à resolução de problemas; o estabelecimento do papel do professor como mediador e facilitador da aprendizagem, em relação horizontal com o educando; a problematização, reflexão e experimentação da realidade, de maneira criativa, com promoção do trabalho interdisciplinar; e a interação indissociável entre teoria e prática (Bacich \& Moran, 2018; Diesel, Baldez \& Martins, 2017; Fernandes, Soares, Ribeiro, Sousa \& Ribeiro, 2018; Freire, 2015).

Em contrapartida, devido a elementos históricos, estruturais e culturais predominantes em nosso país, o pleno exercício das MAs pode ser um grande desafio. Dentre os fatores que influenciam tal cenário, emergem o hábito da educação tradicional; a fragilidade na formação pedagógica de professores e tutores; a deficiência de projetos políticos pedagógicos integrados e flexíveis; a carência de estruturas físicas e gerenciais adequadas; a alta rotatividade de interlocutores sobre o assunto nas secretarias de saúde; dificuldades burocráticas diversas, dentre outros (Custódio, Peixoto, Arruda, Vieira, Sousa \& Ávila, 2019; Daltro \& Pondé, 2016; De-Carli, Silva, Zafalon, Mitre, Pereira, Bomfim \& Theobald, 2019; Gomes, Barbosa \& Ferla, 2016; Morán, 2015).

Em face ao exposto, o presente artigo pretende aprofundar e sistematizar conhecimentos sobre a utilização de estratégias de MAs em processos de EPS, por meio de uma revisão bibliográfica sistemática integrativa de trabalhos científicos produzidos em âmbito nacional.

\section{Metodologia}

Trata-se de um de uma pesquisa de natureza qualitativa (Gil, 1994) que apresenta como método a revisão sistemática integrativa. A revisão sistemática se caracteriza pelo planejamento, sistematização e escolha de métodos criteriosos na coleta e análise dos dados de uma revisão. Já o estudo integrativo, busca sintetizar o que foi produzido cientificamente sobre um determinado tema em certo período de tempo, além de confluir trabalhos pautados em diferentes abordagens metodológicas. 
Assim sendo, esse método possibilita a busca, síntese e análise crítica do assunto investigado, bem como a percepção sobre o estado atual do conhecimento e a deteç̧ão de possíveis lacunas para embasar a elaboração de novas pesquisas (Castro, Saconato, Guidugli, \& Clark, 2002; Whittemore \& Knafl, 2005).

Enquanto estratégia metodológica, utilizou-se de seis etapas, conforme a recomendação de Botelho, Cunha e Macedo (2011): 1) Elaboração do tema, hipóteses e pergunta do estudo, delimitando objetivos e palavras-chave; 2) Estabelecimento de critérios de inclusão, exclusão e bases de dados; 3) Identificação dos estudos pré-selecionados e selecionados, formando o banco de dados; 4) Categorização das pesquisas escolhidas, extraindo e organizando informações; 5) Análise, discussão e interpretação dos resultados, aplicando métodos críticos ou estatísticos; 6) Síntese e apresentação da revisão, mostrando as evidências encontradas.

Diante disso, a busca de literatura envolveu todas as bases de dados disponíveis na Biblioteca Virtual em Saúde (BVS) e as palavras-chave (tw:(metodologias ativas)) and (tw:(educação permanente em saúde)) foram utilizadas no campo "título, resumo, assunto", sendo a coleta de dados realizada no mês de julho de 2020. Enquanto critérios de inclusão, foram elencados estudos disponibilizados na íntegra em língua portuguesa, produzidos nos últimos cinco anos, que apresentassem a utilização de estratégias de MAs em processos de EPS, independente do contexto de abordagem e procedimentos metodológicos. Foram excluídas da amostra bibliografias duplicadas no momento da geração dos dados.

Como resultado da busca, foram obtidos 21 trabalhos científicos, sendo que dois não estavam disponíveis na íntegra e um deles aparecia de forma duplicada. Dos 18 estudos, um se tratava de tese de doutorado, um de um livro e os demais de artigos científicos. Após isso, os mesmos foram submetidos à leitura integral com a finalidade de verificar o enquadramento à abordagem temática, sendo que todos atenderam a esse critério. Por fim, estabeleceu-se a mostra de 18 pesquisas para análise e discussão dos dados, de acordo com o fluxograma explicativo apresentado (Figura 1).

Figura 1. Fluxograma explicativo dos estudos selecionados na BVS

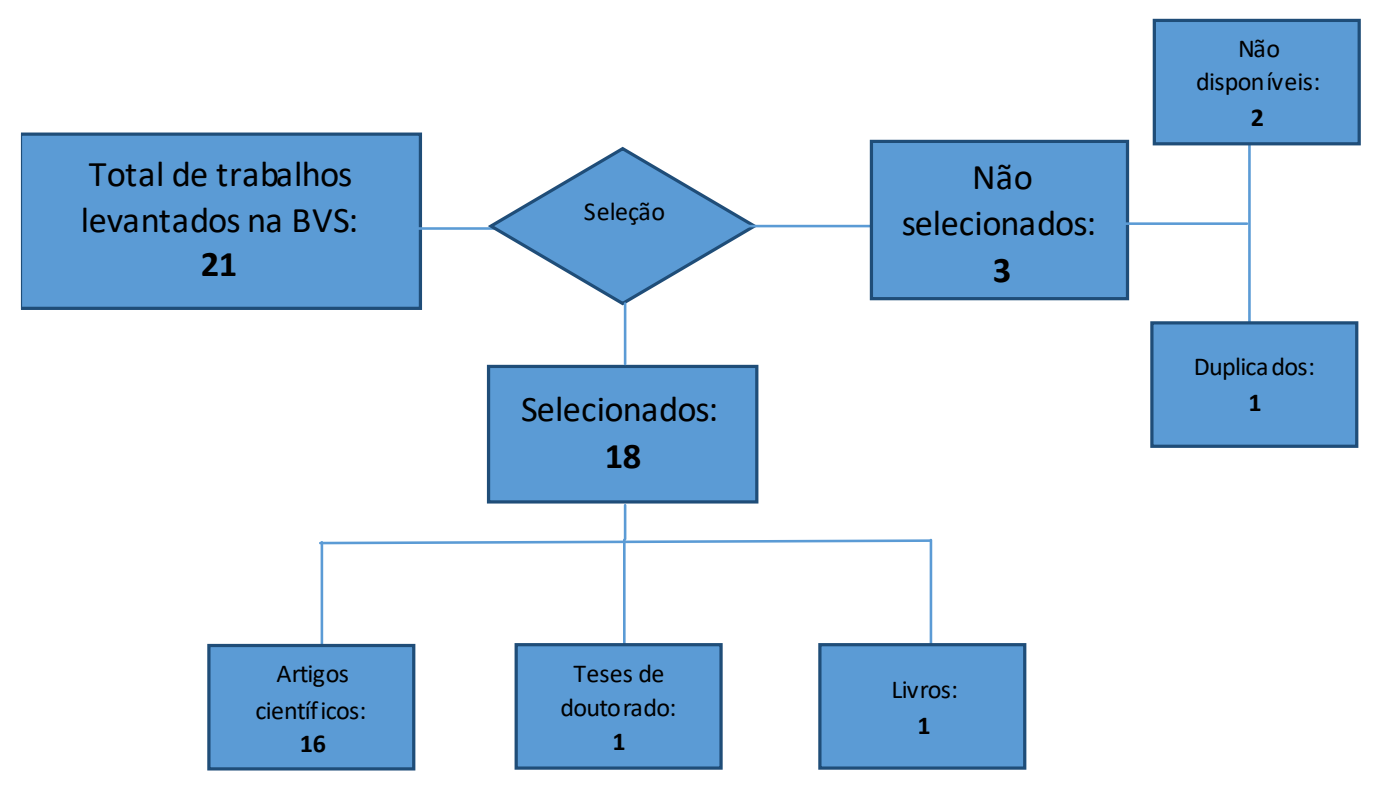

Fonte: Autores, com base na BVS (2020).

Em relação à análise dos dados selecionados, foi utilizada a proposta de matriz de síntese (Botelho, Cunha \& Macedo, 2011), ferramenta destinada a organizar e categorizar os dados bibliográficos em diferentes aspectos, conforme a criatividade 
do pesquisador, a exemplo do quadro explicativo apresentado (Quadro 1).

Quadro 1. Exemplo de matriz de síntese e análise construída para fins desse estudo.

\begin{tabular}{|c|c|c|c|c|c|c|c|c|}
\hline Revista & Área & Ano & Autor & Modalidade & Tema & $\begin{array}{c}\text { Núcleo de } \\
\text { sentido 1 }\end{array}$ & $\begin{array}{c}\text { Núcleo de } \\
\text { sentido 2 }\end{array}$ & $\begin{array}{c}\text { Núcleo de } \\
\text { sentido X... }\end{array}$ \\
\hline Artigo 1 & & & & & & & & \\
\hline Artigo 2 & & & & & & & & \\
\hline $\begin{array}{c}\text { Artigo } \\
\text { X... }\end{array}$ & & & & & & & & \\
\hline
\end{tabular}

Fonte: Autores (2020).

De acordo com a análise dos dados, foram construídos cinco eixos temáticos centrais, elaborando-se as seguintes categorias de sentido: 1) Metodologias ativas: princípios e definições; 2) Metodologias ativas: possibilidades de estratégias de ensino; 3) Metodologias ativas e estratégias avaliativas: possibilidades e reflexões; 4) Currículos integrados e flexíveis: perspectivas de inovação; 5) Tecnologias de Informação e Comunicação: desafios e potencialidades.

\section{Resultados e Discussão}

A partir dos dados, foi elaborada uma tabela sinóptica (Tabela 1), a qual congregou os seguintes aspectos considerados relevantes para caracterização dos trabalhos: revista; área do periódico; ano de publicação; autor da pesquisa; modalidade; e tema de estudo.

Tabela 1. Caracterização dos estudos.

\begin{tabular}{|c|c|c|c|c|c|}
\hline Revista & $\begin{array}{l}\text { Área do } \\
\text { periódico }\end{array}$ & Ano & Autor & Modalidade & Tema do estudo \\
\hline Saúde Debate & Saúde coletiva & 2019 & $\begin{array}{l}\text { Santos, P. Z. dos, } \\
\text { Dias, J. I., \& Alves, } \\
\text { R. B. }\end{array}$ & $\begin{array}{l}\text { Relato de } \\
\text { experiência }\end{array}$ & $\begin{array}{l}\text { Atividade de EPS com agentes } \\
\text { comunitários de saúde (ACSs). }\end{array}$ \\
\hline $\begin{array}{l}\text { Cad. Saúde } \\
\text { Colet. }\end{array}$ & Saúde coletiva & 2019 & $\begin{array}{l}\text { De-Carli, A. D., } \\
\text { Silva, A. D. da M., } \\
\text { Zafalon, E. J., Mitre, } \\
\text { S. M., Pereira, P. Z., } \\
\text { Bomfim, R. A., } \\
\text { Theobald, M. R. }\end{array}$ & Pesquisa qualitativa & $\begin{array}{l}\text { Percepção de alunos sobre uma } \\
\text { disciplina com uso de MAs. }\end{array}$ \\
\hline Saúde Debate & Saúde coletiva & 2019 & $\begin{array}{l}\text { Souza, R. M. P., \& } \\
\text { Costa, P. P. }\end{array}$ & $\begin{array}{l}\text { Relato de } \\
\text { experiência }\end{array}$ & $\begin{array}{c}\text { Relato da concepção e implementação } \\
\text { de cursos de especialização em saúde } \\
\text { pública. }\end{array}$ \\
\hline Ciência Plural & Saúde coletiva & 2019 & Noro, L. & $\begin{array}{l}\text { Relato de } \\
\text { Experiência }\end{array}$ & $\begin{array}{l}\text { Relato do desenvolvimento de um } \\
\text { currículo integrado com MAs. }\end{array}$ \\
\hline $\begin{array}{l}\text { Rev. bras. educ. } \\
\text { med. }\end{array}$ & $\begin{array}{l}\text { Educação na } \\
\text { saúde }\end{array}$ & 2019 & $\begin{array}{c}\text { Custódio, J. B., } \\
\text { Peixoto, M. das G. } \\
\text { B., Arruda, C. A. M., } \\
\text { Vieira, D. V. F., } \\
\text { Sousa, M. do S. de, }\end{array}$ & Pesquisa qualitativa & $\begin{array}{l}\text { Percepção de docentes sobre a formação } \\
\text { médica em saúde coletiva. }\end{array}$ \\
\hline
\end{tabular}


\& Ávila, M. M. M.

\begin{tabular}{|c|c|c|c|c|c|}
\hline Interface & $\begin{array}{l}\text { Educação, } \\
\text { comunicação e } \\
\text { saúde }\end{array}$ & 2019 & $\begin{array}{l}\text { Azevedo, C. R. F. de, } \\
\quad \text { \& Gomes, R. }\end{array}$ & Pesquisa qualitativa & $\begin{array}{l}\text { Capacitação de tutores e facilitadores } \\
\text { em EPS. }\end{array}$ \\
\hline $\begin{array}{l}\text { Rev. bras. educ. } \\
\text { med. }\end{array}$ & $\begin{array}{l}\text { Educação na } \\
\text { saúde }\end{array}$ & 2018 & $\begin{array}{l}\text { Conceição, C. V. da, } \\
\text { \& Moraes, M. A. A. } \\
\text { de. }\end{array}$ & $\begin{array}{l}\text { Pesquisa quanti- } \\
\text { qualitativa }\end{array}$ & $\begin{array}{l}\text { Percepção de estudantes e docentes } \\
\text { sobre um currículo com MAs. }\end{array}$ \\
\hline $\begin{array}{l}\text { Rev. enferm. } \\
\text { UFPE }\end{array}$ & Enfermagem & 2018 & $\begin{array}{l}\text { Fernandes, M. A., } \\
\text { Soares, N. S. A., } \\
\text { Ribeiro, I. A. P., } \\
\text { Sousa, C. D. C. M., } \\
\text { \& Ribeiro, H. K. P. }\end{array}$ & Pesquisa qualitativa & $\begin{array}{c}\text { Capacitação de trabalhadores da saúde } \\
\text { mental com uso de MAs. }\end{array}$ \\
\hline Saúde Debate & Saúde coletiva & 2018 & $\begin{array}{l}\text { Pinheiro, G. E. W., } \\
\text { Azambuja, M. S. de, } \\
\text { \& Bonamigo, A. W. }\end{array}$ & Pesquisa qualitativa & $\begin{array}{l}\text { Compreensão da EPS na estratégia de } \\
\text { saúde da família. }\end{array}$ \\
\hline $\begin{array}{l}\text { Rev. enferm. } \\
\text { UFPE }\end{array}$ & Enfermagem & 2018 & $\begin{array}{l}\text { Ferreira, J., Celuppi, } \\
\text { I. C., Baseggio, L., } \\
\text { Savi Geremia, D., } \\
\text { Larentes, G. F., \& } \\
\text { Hilleshein, A. C. }\end{array}$ & $\begin{array}{l}\text { Relato de } \\
\text { experiência }\end{array}$ & $\begin{array}{c}\text { Oficinas de EPS com gestores } \\
\text { municipais. }\end{array}$ \\
\hline $\begin{array}{l}\text { Rev. enferm. } \\
\text { UERJ }\end{array}$ & Enfermagem & 2017 & $\begin{array}{l}\text { Lopes, M. T. S. R., } \\
\text { Labegalini, C. M. G., } \\
\text { \& Baldissera, V. D. } \\
\text { A. }\end{array}$ & $\begin{array}{c}\text { Revisão } \\
\text { bibliográfica }\end{array}$ & $\begin{array}{c}\text { Preceitos teóricos da EPS para a } \\
\text { utilização da Política Nacional de } \\
\text { Humanização. }\end{array}$ \\
\hline Rev. APS & Saúde coletiva & 2017 & $\begin{array}{l}\text { Vasconcelos, M. I. } \\
\text { O., Farias, Q. L. T., } \\
\text { Nascimento, F. G., } \\
\text { Cavalcante, A. S. P., } \\
\text { Mira, Q. L. M., \& } \\
\text { Queiroz, M. V. O. }\end{array}$ & $\begin{array}{c}\text { Revisão } \\
\text { bibliográfica }\end{array}$ & $\begin{array}{l}\text { Educação em saúde para hipertensos na } \\
\text { mudança do Programa de Saúde da } \\
\text { família para Estratégia de Saúde da } \\
\text { Família. }\end{array}$ \\
\hline
\end{tabular}

\begin{tabular}{|c|c|c|c|c|c|}
\hline Livro UNASUS & $\begin{array}{l}\text { Educação na } \\
\text { saúde }\end{array}$ & 2017 & $\begin{array}{c}\text { Nascimento, D. D. G. } \\
\text { D., Kodjaoglanian, } \\
\text { V. L., De Carli, A. } \\
\text { D., Loureiro, M. D. } \\
\text { R., \& Moraes, S. H. } \\
\text { M. D. }\end{array}$ & $\begin{array}{l}\text { Relato de } \\
\text { experiência }\end{array}$ & $\begin{array}{l}\text { Estratégias de ensino a distância para a } \\
\text { formação de tutores. }\end{array}$ \\
\hline $\begin{array}{l}\text { Trab. Educ. } \\
\text { Saúde }\end{array}$ & $\begin{array}{l}\text { Educação na } \\
\text { saúde }\end{array}$ & 2016 & $\begin{array}{c}\text { Gigante, R. L., \& } \\
\text { Campos, G. W. de S. }\end{array}$ & $\begin{array}{c}\text { Revisão } \\
\text { bibliográfica }\end{array}$ & $\begin{array}{c}\text { Discussão dos relatórios da } \\
\text { Conferências Nacionais de Saúde e de } \\
\text { documentos oficiais do SUS sobre a } \\
\text { formação de recursos humanos e MAs. }\end{array}$ \\
\hline Psic. da Ed. & $\begin{array}{l}\text { Psicologia da } \\
\text { Educação }\end{array}$ & 2016 & $\begin{array}{l}\text { Daltro, M. R., \& } \\
\text { Pondé, M. P. }\end{array}$ & $\begin{array}{l}\text { Relato de } \\
\text { experiência }\end{array}$ & $\begin{array}{l}\text { Reformulação curricular de um curso de } \\
\text { psicologia. }\end{array}$ \\
\hline Rev. da ABENO & Odontologia & 2016 & $\begin{array}{l}\text { Caldarelli, P. G., \& } \\
\text { Haddad, A. E. }\end{array}$ & $\begin{array}{c}\text { Revisão } \\
\text { bibliográfica }\end{array}$ & $\begin{array}{l}\text { Teleodontologia para a formação e } \\
\text { capacitação em odontologia. }\end{array}$ \\
\hline $\begin{array}{c}\text { Vigil. sanit. em } \\
\text { debate }\end{array}$ & $\begin{array}{l}\text { Vigilância } \\
\text { sanitária }\end{array}$ & 2016 & $\begin{array}{l}\text { Guimarães, I. F., \& } \\
\text { Corvino, M. P. F. }\end{array}$ & Pesquisa qualitativa & $\begin{array}{l}\text { Identificação da EPS na vigilância } \\
\text { sanitária de um município. }\end{array}$ \\
\hline
\end{tabular}




\begin{tabular}{|c|c|c|c|c|c|}
\hline $\begin{array}{c}\text { Tese de } \\
\text { Doutorado }\end{array}$ & Odontologia & 2015 & Fonseca, G. S. & Pesquisa qualitativa & $\begin{array}{l}\text { Construção de estágio curricular pela } \\
\text { interação ensino-serviço e prática na } \\
\text { Atenção Primária à Saúde (APS). }\end{array}$ \\
\hline
\end{tabular}

Fonte: Autores com base nos dados da BVS (2020).

Baseando-se na tabela, é possível observar que seis estudos foram publicados em periódicos da área de saúde coletiva; quatro no campo da educação na saúde; três no ramo da enfermagem; dois sobre odontologia; um na área de educação, comunicação e saúde; um no círculo de psicologia da educação; e um diz respeito à vigilância sanitária. Em relação ao perfil metodológico aplicado, sete dos materiais levantados se estruturam como pesquisas qualitativas e um como quali-quantitativo, cinco são revisões de literatura e cinco relatos de experiência. No que diz respeito aos temas identificados, nove se relacionam com atividades de capacitações no âmbito do SUS, voltadas a gestores, trabalhadores e/ou usuários; sete abordam as percepções sobre a elaboração de currículos com abordagem flexível e integrada no contexto de cursos e Universidades; e dois se relacionam com busca documental sobre EPS e MAs no SUS.

Uma segunda tabela (Tabela 2) foi confeccionada com o intuito de identificar os princípios e estratégias de MAs abordadas em cada trabalho.

Tabela 2. Princípios e estratégias de Mas.

\begin{tabular}{|c|c|c|c|}
\hline Revista & Autor & Princípios & Estratégias de MAs \\
\hline $\begin{array}{l}\text { Saúde } \\
\text { Debate }\end{array}$ & $\begin{array}{l}\text { Santos, P. Z. dos, Dias, } \\
\text { J. I., \& Alves, R. B. } \\
(2019) \text {. }\end{array}$ & $\begin{array}{l}\text { Integração entre teoria e prática; reflexão da } \\
\text { realidade e do processo de trabalho; } \\
\text { intervenção e ações intersetoriais.. }\end{array}$ & $\begin{array}{l}\text { Elaboração de maquete; visita local; trabalho } \\
\text { conjunto com a Defesa Civil; recursos audiovisuais; } \\
\text { role-play; e rodas de conversa. }\end{array}$ \\
\hline $\begin{array}{l}\text { Cad. } \\
\text { Saúde } \\
\text { Colet. }\end{array}$ & $\begin{array}{l}\text { De-Carli, A. D., } \\
\text { Silva, A. D. da M., } \\
\text { Zafalon, E. J., Mitre, } \\
\text { S. M., Pereira, P. Z., } \\
\text { Bomfim, R. A., } \\
\text { Theobald, M. R. } \\
\text { (2019). }\end{array}$ & $\begin{array}{l}\text { Autonomia, iniciativa e criatividade; } \\
\text { colaboração e comunicação; integração entre } \\
\text { teoria e prática; visão crítico-reflexiva. }\end{array}$ & $\begin{array}{l}\text { Vivência dos cenários de prática no SUS; discussão } \\
\text { problematizadora na construção da disicplina com o } \\
\text { aluno ativo nessa construção; avaliação formativa da } \\
\text { disciplina; seminários; exposição dialogada; síntese } \\
\text { de diálogos; dramatizações; músicas; dinâmicas; e } \\
\text { autoavaliação permanente. }\end{array}$ \\
\hline $\begin{array}{l}\text { Saúde } \\
\text { Debate }\end{array}$ & $\begin{array}{l}\text { Souza, R. M. P., \& } \\
\text { Costa, P. P. (2019). }\end{array}$ & $\begin{array}{l}\text { Protagonismo do aluno no processo } \\
\text { educativo; saberes já acumulados; prática } \\
\text { cotidiana do trabalho; valorização do } \\
\text { território de atuação; construção colaborativa } \\
\text { e ativa do conhecimento. }\end{array}$ & $\begin{array}{l}\text { Construção do curso com base na realidade do SUS e } \\
\text { de forma conjunta com os trabalhadores; oficinas de } \\
\text { diálogo; compartilhamento de experiências; arco de } \\
\text { Charles Maguerez; seminários; e trabalho em redes } \\
\text { entre as instituições. }\end{array}$ \\
\hline $\begin{array}{l}\text { Ciência } \\
\text { Plural }\end{array}$ & Noro, L. (2019). & $\begin{array}{l}\text { Integração entre teoria e prática; educação } \\
\text { interdisciplinar; criatividade e reflexão; } \\
\text { construção ativa e colaborativa do } \\
\text { conhecimento. }\end{array}$ & $\begin{array}{l}\text { Integração de conhecimentos pela elaboração de } \\
\text { eixos curriculares com a participação discente; } \\
\text { problematização dos currículos; e vivência da } \\
\text { realidade do SUS. }\end{array}$ \\
\hline $\begin{array}{l}\text { Rev. bras. } \\
\text { educ. med. }\end{array}$ & $\begin{array}{l}\text { Custódio, J. B., } \\
\text { Peixoto, M. das G. } \\
\text { B., Arruda, C. A. M., } \\
\text { Vieira, D. V. F., } \\
\text { Sousa, M. do S. de, } \\
\text { \& Ávila, M. M. M. } \\
\text { (2019). }\end{array}$ & $\begin{array}{l}\text { Papel ativo do aluno na aprendizagem; } \\
\text { integração entre teoria e prática; } \\
\text { interdisciplinaridade. }\end{array}$ & $\begin{array}{l}\text { Problematização; seminários; trabalho em pequenos } \\
\text { grupos; relato crítico de experiência; mesa redonda; } \\
\text { integração entre eixos de formação; planejamento } \\
\text { compartilhado de disciplinas; e role play. }\end{array}$ \\
\hline
\end{tabular}


Interface

Azevedo, C. R. F. de, \& Gomes, R. (2019).
Redes de comunicação; construção coletiva do conhecimento; aprendizado na prática profissional; diálogo horizontal; troca de saberes e afetos; autoaprendizagem; criatividade e reflexão; autonomia do sujeito.

Aprendizagem cooperativa; comunicação; raciocínio crítico.
Aprendizagem baseada em problemas; problematização; simulações realísticas e filmes; portfólio reflexivo; avaliação somativa; trabalho de conscientização de percurso pela narrativa reflexiva; trabalho em conjunto com outras instituições; trabalho em grupo; escrita narrativa; integração com a realidade do trabalho.

Atividades em pequenos grupos e atividades de simulação de situações da realidade.
Rev. bras. \& Moraes, M. A. A. educ. med. de. (2018).
Fernandes, M. A.,

Rev. Soares, N. S. A.,

enferm. Ribeiro, I. A. P.,

UFPE Sousa, C. D. C. M. \& Ribeiro, H. K. P. (2018).
Interação entre teoria e prática; autonomia do educando; redes de apoio; valorização de saberes prévios; pensamento crítico e reflexivo.
Diagnóstico situacional e problematização; peça teatral; visita territorial; uso do Team Based Learning (TBL); experiência real e experiência simulada; relatos de experiência e debates.
Pinheiro, G. E. W.,

Saúde Azambuja, M. S. de, Debate \& Bonamigo, A. W. (2018).

Ferreira, J., Celuppi,

Rev. I. C., Baseggio, L.,

enferm. Savi Geremia, D.,

Larentes, G. F., \& Hilleshein, A. C. (2018).

Rev. Lopes, M. T. S. R., enferm. Labegalini, C. M. G., UERJ \& Baldissera, V. D. A. (2017).

Vasconcelos, M. I.

O., Farias, Q. L. T.,

Nascimento, F. G.,

Rev. APS Cavalcante, A. S. P., Mira, Q. L. M., \& Queiroz, M. V. O. (2017).

Nascimento, D. D. G.

D., Kodjaoglanian,

Livro V. L., De Carli, A.

UNASUS D., Loureiro, M. D.

R., \& Moraes, S. H.

M. D. (2017).
Trocas de saberes; integração entre teoria e prática; construção coletiva do conhecimento.
Problematização da realidade; discussão e troca de experiências do trabalho; seminários; e construção coletiva de projeto.
Integração entre teoria e prática; pensamento crítico-reflexivo; trabalho em equipe; comunicação assertiva; construção colaborativa e coletiva do conhecimento.
Roda de conversa; dinâmica do dó; trabalho em equipes; elaboração de cartazes.
Articulação entre teoria e prática; dialogicidade; valorização dos atores envolvidos.
Grupalidade; exposição dialogada; problematização; e método da roda.
Atitudes autônomas e sujeitos ativos; corresponsabilização; troca de saberes.
Rodas de conversa; oficinas educativas; peças teatrais; abordagem grupal com materiais lúdicos; grupo focal; visita domiciliar.
Articulação teórico-prática; construção do conhecimento de forma colaborativa; integração ensino-serviço; reflexão da realidade; autonomia para a aprendizagem.
Plataforma AVA Moodlee; debates; oficinas de encontro; problematização; rodas de conversa.
Trab. Gigante, R. L., \&

Educ. Campos, G. W. de S.

Saúde (2016).
Aprendizagem significativa; cotidiano como fonte de aprendizagem; aprender a aprender.
Espaços coletivos de cogestão e práticas integradoras. 


\begin{tabular}{|c|c|c|c|}
\hline $\begin{array}{l}\text { Psic. da } \\
\text { Ed. }\end{array}$ & $\begin{array}{l}\text { Daltro, M. R., \& } \\
\text { Pondé, M. P. (2016). }\end{array}$ & $\begin{array}{l}\text { Desenvolvimento da autonomia; capacidade } \\
\text { crítica; educação interdisciplinar; } \\
\text { aprendizagem na realidade; integração } \\
\text { teórico-prática; aprender fazendo; capacidade } \\
\text { de comunicação; pró-atividade. }\end{array}$ & $\begin{array}{l}\text { Problematização; aprendizagem baseada em } \\
\text { problemas; currículo em eixos e módulos com } \\
\text { circuitos dialógicos; diálogos temáticos; consulta à } \\
\text { comunidade; trabalhos em grupos e equipes. }\end{array}$ \\
\hline $\begin{array}{r}\text { Rev. da } \\
\text { ABENO }\end{array}$ & $\begin{array}{l}\text { Caldarelli, P. G., \& } \\
\text { Haddad, A. E. } \\
(2016) .\end{array}$ & $\begin{array}{l}\text { Integração ensino-serviço; } \quad \text { trabalho } \\
\text { interdisciplinar ou em redes. }\end{array}$ & $\begin{array}{l}\text { Parcerias entre órgãos; teleassistência; teleeducação; } \\
\text { e teleconsultoria. }\end{array}$ \\
\hline $\begin{array}{l}\text { Vigil. } \\
\text { sanit. em } \\
\text { debate }\end{array}$ & $\begin{array}{l}\text { Guimarães, I. F., \& } \\
\text { Corvino, M. P. F. } \\
\text { (2016). }\end{array}$ & $\begin{array}{l}\text { Troca de experiências; articulação com a } \\
\text { realidade; pensamento crítico-reflexivo; } \\
\text { construção coletiva do conhecimento; } \\
\text { aprendizagem significativa. }\end{array}$ & $\begin{array}{l}\text { Discussões em grupos focais e problematização do } \\
\text { processo de trabalho. }\end{array}$ \\
\hline $\begin{array}{c}\text { Tese de } \\
\text { Doutorado }\end{array}$ & $\begin{array}{l}\text { Fonseca, G. S. } \\
(2015) \text {. }\end{array}$ & $\begin{array}{l}\text { Educação pela experiência; ressignificação do } \\
\text { raciocínio clínico; reflexão e experimentação } \\
\text { dos espaços; trabalho em equipe. }\end{array}$ & $\begin{array}{l}\text { Dinâmicas; estágios articulados; diários de campo; } \\
\text { grupos focais; entrevistas; observação participante; } \\
\text { metáfora da realidade pela narrativa do cotidiano. }\end{array}$ \\
\hline
\end{tabular}

Fonte: Autores, com base nos dados da BVS (2020).

A partir dos elementos da tabela, foram construídos núcleos de sentido que serão discutidos a seguir: princípios e definições; possibilidades de estratégias de ensino; estratégias avaliativas; currículos integrados e flexíveis; Tecnologias de Informação e Comunicação (TICs).

\subsection{Metodologias ativas: princípios e definições}

Observa-se na análise que todos os materiais levantados se preocupam em apresentar os princípios que envolvem as MAs. No aspecto das definições, quinze trabalhos conceituam as MAs como uma metodologia de ensino-aprendizagem inovadora e alternativa ao modelo tradicional de educação, sem maiores delimitações (Azevedo \& Gomes, 2019; Caldarelli \& Haddad, 2016; Conceição \& Moraes, 2018; Custódio, Peixoto, Arruda, Vieira, Sousa \& Ávila, 2019; Daltro \& Pondé, 2016; De-Carli, Silva, Zafalon, Mitre, Pereira, Bonfim, Theobald, 2019; Fernandes, Soares, Ribeiro, Sousa \& Ribeiro, 2018; Ferreira, Celuppi, Baseggio, Geremia, Larentes \& Hilleshein, 2018; Fonseca, 2015; Gigante \& Campos, 2016; Lopes, Labegalini \& Baldissera, 2017; Noro, 2019; Pinheiro, Azambuja \& Bonamigo, 2018; Souza \& Costa, 2019; Vasconcelos, Farias, Nascimento, Cavalcante, Mira \& Queiroz, 2017).

No tocante aos princípios que norteiam as MAs, construiu-se um fluxograma ilustrativo (Figura 2) congregando-os em oito esferas: 1) Integração entre teoria, prática, experiência e territórios; 2) Problematização, reflexão e senso crítico da realidade; 3) Trabalho em equipe, colaboração e comunicação; 4) Interdisciplinaridade e intersetorialidade; 5) Autonomia, iniciativa e protagonismo do educando; 6) Construção ativa, colaborativa e coletiva do conhecimento; 7) Diálogos horizontais e troca de saberes; 8) Aprendizagem significativa (Azevedo \& Gomes, 2019; Caldarelli \& Haddad, 2016; Conceição \& Moraes, 2018; Custódio, Peixoto, Arruda, Vieira, Sousa \& Ávila, 2019; Daltro \& Pondé, 2016; De-Carli, Silva, Zafalon, Mitre, Pereira, Bonfim, Theobald, 2019; Fernandes, Soares, Ribeiro, Sousa \& Ribeiro, 2018; Ferreira, Celuppi, Baseggio, Geremia, Larentes \& Hilleshein, 2018; Fonseca, 2015; Gigante \& Campos, 2016; Guimarães \& Corvino, 2016; Lopes, Labegalini \& Baldissera, 2017; Nascimento, Kodjaoglanian, De Carli, Loureiro \& Moraes, 2017; Noro, 2019; Pinheiro, Azambuja \& Bonamigo, 2018; Santos, Dias \& Alves, 2019; Souza \& Costa, 2019; Vasconcelos, Farias, Nascimento, Cavalcante, Mira \& Queiroz, 2017). 
Figura 2. Fluxograma ilustrativo sobre os Princípios das Mas.

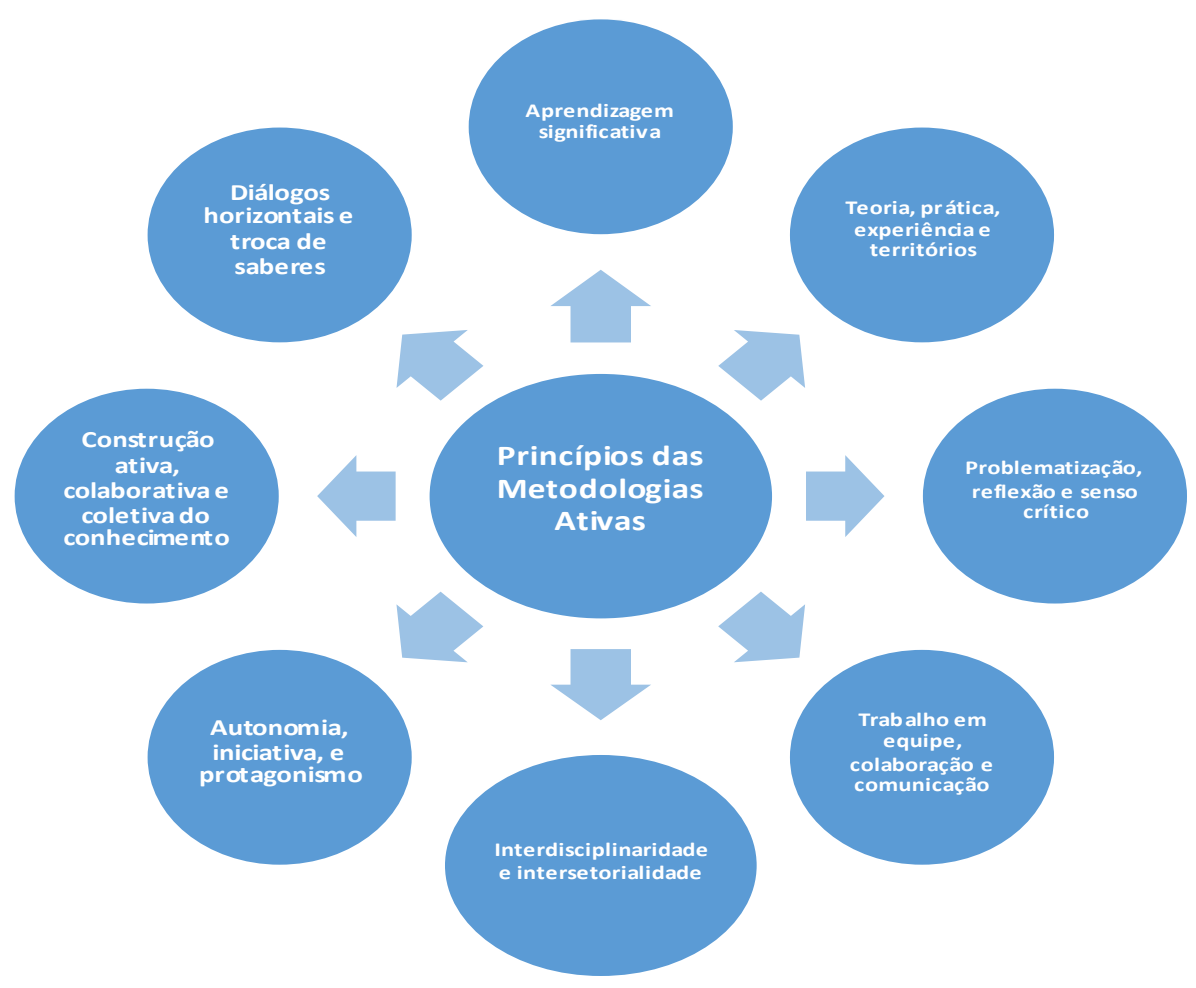

Fonte: Autores, com base nos dados das pesquisas da BVS (2020).

\subsection{Metodologias ativas: possibilidades de estratégias de ensino}

Todos os trabalhos obtidos pela metodologia do presente estudo citam a utilização de alguma estratégia de aplicação das MAs no contexto das EPS, evidenciando, assim, uma grande variedade de possibilidades e a necessidade da composição criativa de ferramentas que inovem e facilitem o processo de ensino-aprendizagem.

Para compor as reflexões e aprofundamentos que aqui se pretende, tais conteúdos foram agrupados em três subcategorias, a serem abordadas na sequência, quais sejam: 1) Trabalhos em grupos, equipes e ações em redes: construindo coletivamente práticas formativas; 2) Experimentação e problematização da realidade: construindo conhecimento a partir da vivência; 3) Seminários, diálogos, dinâmicas e oficinas: compartilhamento de saberes e práticas possíveis.

\subsubsection{Trabalho em grupo, equipes e ações em redes: construindo coletivamente práticas formativas}

Torres, Alcântara e Irala (2004) e Camurça, Dantas, Rodrigues, Teixeira e Caldas (2020) elucidam que as MAs pautadas em trabalhos em grupos propiciam a convivência, a interdependência e a resolução de problemas de maneira conjunta, em uma relação cooperativa, colaborativa e interdisciplinar entre os atores envolvidos. Nessa subcategoria, identificaram-se treze trabalhos abordando as seguintes modalidades: aprendizagem por pares ou times, como o Team Based Learning (TBL); os grupos focais, reflexivos e interdisciplinares; as articulações e ações em redes intersetoriais entre instituições, órgãos e comunidade (Azevedo \& Gomes, 2019; Caldarelli \& Haddad, 2016; Conceição \& Moraes, 2018; Daltro \& Pondé, 2016; Fernandes, Soares, Ribeiro, Sousa \& Ribeiro, 2018; Ferreira, Celuppi, Baseggio, Geremia, Larentes \& Hilleshein, 2018; Fonseca, 2015; Gigante \& Campos, 2016; Guimarães \& Corvino, 2016; Lopes, Labegalini \& Baldissera, 2017; Santos, Dias \& Alves, 2019; Souza \& Costa, 2019; Vasconcelos, Farias, Nascimento, Cavalcante, Mira \& Queiroz, 2017).

A respeito do TBL, traduzido como aprendizagem baseada em equipes, os aprendizes são separados em times, pares ou equipes e cada grupo recebe uma temática a ser desenvolvida. Inicialmente, cada pessoa realiza uma reflexão individual 
acerca do assunto e por fim ocorre a problematização coletivamente, sendo elaborada uma conclusão comum para representar o grupo (Hartz \& Schlatter, 2016). Nessa lógica, o estudo de Fernandes, Soares, Ribeiro, Sousa e Ribeiro (2018) faz uso do TBL como método para familiarizar previamente os profissionais da saúde acerca de um tema a ser trabalhado em uma atividade educativa e para realizar um diagnóstico situacional sobre as vulnerabilidades territoriais.

Vasconcelos, Farias, Nascimento, Cavalcante, Mira e Queiroz (2017), analisando trabalhos de promoção da Saúde direcionados a hipertensos, relatam que metade dos artigos utilizou a abordagem grupal, como as oficinas e as rodas de conversa. Essas atividades coletivas serviram como respaldo para alterar as estratégias de educação em saúde locais e repensar a capacitação dos profissionais dessa área. Já Custódio, Peixoto, Arruda, Vieira, Sousa e Ávila (2019), ao analisar a percepção de docentes sobre uma disciplina de saúde coletiva por meio da técnica do grupo focal, demonstrou o interesse desses educadores em desenvolver atividades com base em pequenos grupos para que os discentes vivenciassem ao máximo a prática profissional pela simulação da realidade e da resolução de casos clínicos.

Souza e Costa (2019), por sua vez, relataram a importância da atuação em redes, apresentando a potencialidade da estratégia de um curso em saúde coletiva para agregar várias instituições em torno de princípios coletivamente construídos, do apoio mútuo e do compartilhamento de saberes. O estudo de Santos, Dias e Alves (2019) corrobora com essa ideia ao apontar que a atuação conjunta entre ACSs e a Defesa Civil possibilitou a identificação de locais de risco para desastres a partir da vivência da realidade territorial.

Já Cardarelli e Haddad (2016) citam ainda que a teleodontologia, ação de qualificação e apoio ao profissional odontólogo à distância, pôde impulsionar projetos nacionais de atenção à saúde bucal com parcerias entre governo, instituições privadas e órgãos não-governamentais.

\subsubsection{Experimentação e problematização da realidade: construir conhecimento a partir da vivência}

Conforme os preceitos das MAs, os processos educativos devem focar seus esforços para alcançar a formação do ser humano enquanto sujeito ativo, reflexivo, crítico e engajado com a realidade, relacionando intrinsecamente a teoria à prática. Nesse sentido, a aprendizagem pela experiência real ou simulada, em que o discente é instigado a aprender mediante a resolução de problemáticas da prática social, é a proposta do método de aprendizagem baseada em problemas (ABP) ou Problem Based Learning (PBL) (Berbel, 2011; De-Carli, Silva, Zafalon, Mitre, Pereira, Bonfim, Theobald, 2019; Camurça, Dantas, Rodrigues, Teixeira \& Caldas, 2020).

Nesse quesito, foram identificados 15 estudos que discutem as seguintes estratégias: a ABP, como a problematização e o arco de Charles Maguerez; as simulações da realidade, como as dramatizações, as peças teatrais e o role play; e a experimentação problematizadora, como as visitas locais, as vivências das práticas laborais, a observação participante, os diagnósticos situacionais e os diários de campo (Azevedo \& Gomes, 2019; Caldarelli \& Haddad, 2016; Conceição \& Moraes, 2018; Custódio, Peixoto, Arruda, Vieira, Sousa \& Ávila, 2019; Daltro \& Pondé, 2016; De-Carli, Silva, Zafalon, Mitre, Pereira, Bonfim \& Theobald, 2019; Fernandes, Soares, Ribeiro, Sousa \& Ribeiro, 2018; Fonseca, 2015; Gigante \& Campos, 2016; Guimarães \& Corvino, 2016; Lopes, Labegalini \& Baldissera, 2017; Noro, 2019; Santos, Dias \& Alves, 2019; Souza \& Costa, 2019; Vasconcelos, Farias, Nascimento, Cavalcante, Mira \& Queiroz, 2017).

Diferentes dos autores pautaram seus trabalhos em EPS no Arco de Charles Maguerez. De maneira sintética, o Arco, baseado na problematização e na ABP, é uma ferramenta de ensino-aprendizagem caracterizada por: visualização da realidade, elegendo-se um problema; elaboração de pontos centrais da observação; busca da abordagem teórica do assunto; construção de proposições de soluções acerca da problemática; e, por fim, volta à realidade para aplicação das saídas encontradas (Bordenave \& Pereira, 2004). Souza e Costa (2019) apresentaram a utilização desse método pelas instituições da Rede Brasileira de Escolas de Saúde Pública para a formação de um projeto pedagógico ancorado nas demandas da realidade territorial. Já Lopes, 
Labegalini e Baldissera (2017) citam que a problematização é um instrumento importante para a educação ativa ao propor a discussão e a resolução de problemas reais, promovendo a aprendizagem significativa.

Em relação à simulação e experimentação da realidade, a estratégia do role-play consiste em um jogo ou simulação realística, em que os aprendizes reproduzem papéis e vivências de situações como se estivessem na vida real (Rabelo \& Garcia, 2015). Custódio, Peixoto, Arruda, Vieira, Sousa e Ávila (2019) relataram a aplicação dessa ferramenta, aplicando a dramatização aos alunos com a finalidade de reconhecimento da função e prática profissional por meio da experiência de casos simulados.

Enquanto estratégia pedagógica, o diagnóstico situacional, por sua vez, foi utilizado por Santos \& Rigotto (2010) para ampliar a competência de eleger, descrever e explicar os problemas centrais de uma região adstrita em um determinado contexto, a partir da vivência e observação da realidade. O estudo de Fernandes, Soares, Ribeiro, Sousa e Ribeiro (2018) ainda cita a importância da utilização desse recurso para o desenvolvimento da autonomia, responsabilidade e reflexão no processo de ensino-aprendizagem.

Simão, Teixeira, Freitas, Viana \& Pinheiro (2016) relataram o uso do diário de campo para prover um registro sistemático do cotidiano, afirmando a importância desta técnica para aproximar os envolvidos no processo educacional junto à realidade observada. Por sua vez, o trabalho de Fonseca (2015) apresentou a utilização de diários de campo no contexto de estágios curriculares supervisionados, sublinhando a potencialidade desta ferramenta para a construção de metáforas da realidade acerca da clínica ampliada.

\subsubsection{Seminários, diálogos, dinâmicas e oficinas: compartilhamento de saberes e práticas possíveis}

No que tange à operacionalização das MAs, quinze trabalhos utilizam as seguintes técnicas: seminários; mesasredondas; exposições dialogadas; debates temáticos; discussões; relatos críticos de experiências; narrativas reflexivas; rodas de conversas; dinâmicas; oficinas; e elaboração de materiais, entre eles maquetes, cartazes, escritas narrativas e síntese de diálogos (Azevedo \& Gomes, 2019; Caldarelli \& Haddad, 2016; Custódio, Peixoto, Arruda, Vieira, Sousa \& Ávila, 2019; Daltro \& Pondé, 2016; De-Carli, Silva, Zafalon, Mitre, Pereira, Bonfim \& Theobald, 2019; Fernandes, Soares, Ribeiro, Sousa \& Ribeiro, 2018; Ferreira, Celuppi, Baseggio, Geremia, Larentes \& Hilleshein, 2018; Fonseca, 2015; Guimarães \& Corvino, 2016; Lopes, Labegalini \& Baldissera, 2017; Nascimento, Kodjaoglanian, De Carli, Loureiro \& Moraes, 2017; Pinheiro, Azambuja \& Bonamigo, 2018; Santos, Dias \& Alves, 2019; Souza \& Costa, 2019; Vasconcelos, Farias, Nascimento, Cavalcante, Mira \& Queiroz, 2017).

Conforme Davini (2008), os seminários de leitura e debate possibilitam o desenvolvimento da interpretação reflexiva e da leitura independente e o intercâmbio cultural entre os participantes das atividades educativas. Em relação aos diálogos reflexivos, a mesma autora relata que seu núcleo fundamental é a conversação significativa, com a troca de observações, experiências e pontos de vista. Nessa mesma lógica, as dinâmicas e oficinas visam associar o conhecimento teórico à prática, estimulando o pensamento crítico-reflexivo, conversas entre grupos, compartilhamento de saberes, resolução conjunta de problemas e construção coletiva de conhecimento (Ferreira, Celuppi, Baseggio, Geremia, Larentes \& Hilleshein, 2018; Souza \& Costa, 2019).

De-Carli, Silva, Zafalon, Mitre, Pereira, Bonfim e Theobald (2019) relataram a utilização, em sua pesquisa, de seminários, síntese de diálogos e exposição dialogada para a problematização de uma disciplina entre docentes e discentes. Azevedo e Gomes (2019) abordaram o uso da narrativa reflexiva para a capacitação de tutores em EPS, a qual promoveu a aprendizagem significativa, aquisição de competências e habilidades pessoais. O estudo de Custódio, Peixoto, Arruda, Vieira, Sousa e Ávila (2019) ressaltou a preocupação docente em inserir os alunos no ambiente da prática profissional desde o início do curso e, para isso, foram promovidas mesas-redondas com a participação de trabalhadores da saúde. Já o método da roda, 
citado por Lopes, Labegalini e Baldissera (2017) e Cotta, Reis, Campos, Gomes, Antonio e Siqueira-Batista (2013), foi descrito como um espaço coletivo de conversas, debates, "ofertas e demandas".

Nessa perspectiva, Ferreira, Celuppi, Baseggio, Geremia, Larentes e Hilleshein (2018) discorreram sobre atuações conjuntas, citando a dinâmica do nó, construída nos seguintes passos: formação de um círculo pelos participantes e observação das pessoas que se encontravam à direita e à esquerda; dispersão pelo ambiente, desfazendo a roda inicial; e junção das mãos às pessoas visualizadas anteriormente, constituindo-se um grande emaranhado de braços; Por fim, o grupo foi desafiado a desatar os nós formados com o intuito de desenvolver a consciência sobre a necessidade do trabalho coletivo. Santos, Dias e Alves (2019) esboçaram a ação colaborativa ao apresentar a estratégia da produção de uma maquete pela equipe com a finalidade de simular a realidade territorial e identificar áreas passíveis de desastres naturais. Já Ferreira, Celuppi, Baseggio, Geremia, Larentes e Hilleshein (2018) explicitaram o desenvolvimento de cartazes por gestores do SUS a respeito de avanços e desafios profissionais, possibilitando a identificação de barreiras e potencialidades nos distintos municípios.

\subsection{Metodologias ativas e estratégias avaliativas: possibilidades e reflexões}

Uma problemática identificada nos estudos diz respeito às limitações para a composição e aplicação de estratégias de avaliação que se integrem às propostas pautadas nas MAs no âmbito da EPS (De-Carli, Silva, Zafalon, Mitre, Pereira, Bonfim \& Theobald, 2019).

Para Luckesi (2014) e (2018), a ação de avaliar é inerente ao ser humano que, de forma consciente ou inconsciente, realiza escolhas, qualificando a realidade para se obter resultados positivos. Nesse sentido, defende que a avaliação consiste na investigação da qualidade dos fatos, devendo ser um processo amoroso, acolhedor, que objetive soluções, transformações, êxito e diagnóstico da aprendizagem. Dessa forma, precisa ser dinâmica e processual, para além do ato de classificar, selecionar, segregar e excluir. Nessa condição, dois artigos abordaram a temática, citando avaliações formativas e somativas, como o portfólio reflexivo, a autoavaliação permanente e o trabalho de conscientização de percurso pela narrativa reflexiva (Azevedo \& Gomes, 2019; De-Carli, Silva, Zafalon, Mitre, Pereira, Bonfim \& Theobald, 2019).

As atividades avaliativas podem ser utilizadas com duas finalidades: auxiliar e sintetizar o aprendizado. O primeiro caso, diz respeito à técnica formativa, método que visa a progressiva assimilação de conteúdos e avaliação da aprendizagem com a participação ativa do aluno e o uso de seus resultados para direcionar estratégias. Nessa modalidade, está o portfólio, um compilado de arquivos e produções acerca da prática educativa, e a autoavaliação, que possui o intuito de habilitar para a autonomia, iniciativa e colaboração.

O segundo aspecto trata do método somativo, o qual objetiva sintetizar e quantificar a aprendizagem ao final do processo educativo, a exemplo das retroalimentações de percursos e aplicação de exames (Davini, 2008; De-Carli, Silva, Zafalon, Mitre, Pereira, Bonfim \& Theobald, 2019; Luckesi, 2014; Santos, 2016). No que diz respeito às retroalimentações de percursos, o estudo de Azevedo e Gomes (2019) utilizou 20 Trabalhos de Conscientização de Percurso (TCP), oriundos de uma capacitação de tutores e facilitadores em EPS, para explorar êxitos e limitações do uso de narrativas reflexivas enquanto estratégias pedagógicas. O TCP consiste em uma avaliação somativa que utiliza a narrativa da ação educativa, na forma escrita ou falada, com objetivo de reflexão para a conscientização da experiência vivenciada. No caso específico, concluiu-se que o uso das narrativas reflexivas possibilitou uma ressignificação sobre o papel do educador e da educação na direção da construção da autonomia dos sujeitos.

Cabe ressaltar, ainda, que os estudos citados advogam pela importância de avaliações inclusivas, reflexivas, participativas e processuais para as metodologias ativas, ao detrimento dos exames classificatórios, muito utilizados pelo modelo tradicional de ensino. 


\subsection{Currículos integrados e flexíveis: perspectivas de inovação}

Segundo Morán (2015), diferentes instituições educacionais interessadas em promover mudanças que caminhem para a oferta de práticas mais ativas de ensino podem propor transformações curriculares progressivas ou mais abruptas e profundas. Tais opções, segundo o autor, possibilitam um amplo leque de possibilidades e um quadro bastante plural de experiências e configurações curriculares possíveis.

No caminho mais suave, elas mantêm o modelo curricular predominante - disciplinar - mas priorizam o envolvimento maior do aluno, com metodologias ativas como o ensino por projetos de forma mais interdisciplinar, o ensino híbrido ou blended e a sala de aula invertida. Outras instituições propõem modelos mais inovadores, disruptivos, sem disciplinas, que redesenham o projeto, os espaços físicos, as metodologias, baseadas em atividades, desafios, problemas, jogos e onde cada aluno aprende no seu próprio ritmo e necessidade e também aprende com os outros em grupos e projetos, com supervisão de professores orientadores (Morán, 2015, p.15).

Neste sentido, seis das bibliografias estudadas procuraram apresentar reflexões e possibilidades de (re)organização curricular, foco dado às metodologias ativas. Os materiais versaram sobre: integração entre conhecimentos pela elaboração de currículos em eixos ou módulos; convergência entre teoria e prática, como a realização de estágios articulados; construção e problematização de cursos, currículos e disciplinas de forma conjunta, ou seja, com a participação docente, discente, da gestão e do trabalhador de saúde (Daltro \& Pondé, 2016; De-Carli, Silva, Zafalon, Mitre, Pereira, Bonfim \& Theobald, 2019; Custódio, Peixoto, Arruda, Vieira, Sousa \& Ávila, 2019; Fonseca, 2015; Noro, 2019; Souza \& Costa, 2019).

O trabalho de Custódio, Peixoto, Arruda, Vieira, Sousa e Ávila (2019) relata a preocupação de docentes de um curso de medicina na área da saúde coletiva em não segregar teoria e prática. Para eles, a mudança curricular demanda reorganizar o conhecimento na práxis, sendo primordial o viés interdisciplinar, a articulação entre eixos e a capacitação docente para o uso de MAs.

Na mesma perspectiva, Fonseca (2015) demonstra atenção ao tema e apresenta um modelo de Estágio Curricular Supervisionado em odontologia organizado de forma a articular ensino, trabalho e cidadania, promovendo parcerias entre alunos, docentes, trabalhadores e gestores do SUS inclinados em superar a lógica do ensino direcionado a resolver apenas problemas de saúde bucal.

Daltro e Pondé (2016, p.1), por sua vez, abordaram a construção de um projeto político pedagógico de um curso de Psicologia. O modelo de currículo em questão se baseia em módulos e eixos complementares, com distintos objetivos e metodologias. Na proposta composta, seis eixos temáticos foram elaborados com o objetivo de organizar e integrar os componentes curriculares, quais sejam: I. "Ser humano e ciclo de vida"; II. "Fundamentos de psicologia"; III. "Psicologia, sociedade e cultura"; IV. "Intervenções em psicologia"; V. "Pesquisa em psicologia"; VI. "Práticas pré-profissionalizantes" (Daltro \& Pondé, 2016, p.84).

Em reflexão a respeito das abordagens metodológicas a serem empregadas, o curso de organizou em três módulos. No primeiro módulo, destinado a "apresentar a Psicologia, seus objetos de estudo e intervenção, sua fundamentação teórica, técnicas e instrumentos de intervenção" (Daltro \& Pondé, 2016, p.87), tomaram destaque o uso de MAs, como a Aprendizagem Baseada em Problemas (ABP/PBL), estratégia prioritária do $1^{\circ}$ ao $6^{\circ}$ semestre. No segundo módulo, realizado no $7^{\circ}$ ao $8^{\circ}$ semestre, o estudante vivencia uma prática-assistida, intitulada no artigo de Internato, realizado no SUS, além de desenvolver um trabalho de conclusão de curso. Finalmente, no terceiro módulo toma lugar a realização de estágios, do $9^{\circ} \mathrm{e}$ $10^{\circ}$ semestre (Daltro \& Pondé, 2016).

Segundos as autoras, ainda, cada um dos dez semestres possui uma determinada função: I. "Tempo de afiliação institucional e ao discurso das ciências e da academia"; II. "Tempo de identificação da psicologia e suas teorias"; III. "Tempo de desilusão, separação e escolhas”; IV. "Tempo de identificação e curiosidades”; V. "Tempo de ver o outro”; VI. “Tempo de 
desejar e duvidar"; VII. "Tempo de experimentar"; VIII. “Tempo de decidir”; IX. "Tempo de praticar”; X. "Projetos - carreira profissional” (Daltro \& Pondé, 2016, p.85).

Seguindo essa mesma concepção, Souza e Costa (2019) discutem o desenvolvimento de um currículo integrado em odontologia estruturado em cinco módulos a serem trabalhados pela metodologia da problematização: I. Módulos integrados, do $1^{\circ}$ ao $8^{\circ}$ semestre, os quais se constituem nas propostas centrais de formação do curso, voltados a direcionar o estudo e a discussão de como as diferentes áreas de conhecimento e os docentes irão se articular; II. Extensão curricular, do $1^{\circ}$ ao $8^{\circ}$ semestre, baseia-se na inserção da comunidade na aprendizagem discente; III. Flexibilização, do $1^{\circ}$ ao $8^{\circ}$ semestre, com atividades complementares e optativas, dentre elas as pesquisas, práticas extracurriculares, multidisciplinares, interprofissionais, artísticas e um direcionamento formativo singular; IV. Estágio curricular supervisionado, no $9^{\circ}$ e $10^{\circ}$ semestre, com a inserção do aluno nos ambientes do SUS por meio da preceptoria de um trabalhador da saúde local; V. Trabalho de Conclusão do Curso (TCC), do $1^{\circ}$ ao $8^{\circ}$ semestre. Além desses eixos, observa-se na proposta curricular a presença de "áreas verdes" para que o discente se dedique ao estudo individual e ao lazer.

Tais propostas, para além de impactar consideravelmente na formação estudantil, inserindo o estudante de graduação em questões comunitárias, de maneira engajada e ativa, e, aliando indissociavelmente teoria e prática, afirma também sua potência enquanto estratégia de construção de conhecimento junto aos preceitos da EPS. Neste sentido, a Universidade invade de maneira parceira o cotidiano das instituições de saúde, participando conjuntamente da elaboração e execução de diferentes propostas que enfrentem, a partir da conjectura das forças de todas as instituições envolvidas, as variadas problemáticas comunitárias. Tal processo, logo, reposiciona vertiginosamente as práticas educacionais, envolvendo, em uma espiral evolutiva, estudantes, docentes, profissionais, gestores e comunidade na construção compartilhada de conhecimentos, de maneira a aliar teoria à prática e potencializar diferentes vínculos sociais para a ampliação e especialização do cuidado e da formação em saúde.

\subsection{Tecnologias de informação e comunicação: desafios e potencialidades}

Para Morán (2015), a educação formal vem se tornando cada vez mais híbrida, situada em diversos lugares e contextos, entre eles o ambiente digital. Nessa conjuntura, as Tecnologias de Informação e Comunicação (TICs) se tornam ferramentas para a inauguração de novas formas de atividades educacionais, ampliando locais de aprendizagem e possibilitando estratégias, que cada vez mais se aproximam das novas gerações (Pischetola \& Miranda, 2019).

No tocante ao uso das TICs, cinco estudos discutem o tema abordando o ensino híbrido ou à distância (EAD), com a utilização da plataforma AVA Moodlee e a telesaúde, e variados recursos audiovisuais, entre eles filmes e músicas (Azevedo \& Gomes, 2019; Caldarelli \& Haddad, 2016; De-Carli, Silva, Zafalon, Mitre, Pereira, Bonfim \& Theobald, 2019; Nascimento, Kodjaoglanian, De Carli, Loureiro \& Moraes, 2017; Santos, Dias \& Alves, 2019).

Em sua ampla possibilidade de execução, as MAs podem se utilizar das diferentes potências próprias às TICs, as quais inegavelmente possibilitam modos inaugurais de comunicação e interação, em ambientes formais e informais, que ultrapassam variados limites geográficos. Nesse sentido, as MAs podem se utilizar das estratégias de EAD, de propostas de construção de conhecimento pelo ensino remoto e de recursos audiovisuais para propor práticas educacionais criativas (Lázaro, Sato \& Tezani, 2018; Morán, 2015).

$\mathrm{Na}$ esfera da EAD e de processos de educação por ensino remoto, as atividades educativas podem tomar forma por meio de aulas não presenciais e não necessariamente concomitantes para diferentes alunos em tempo e espaço. Ainda, tais TICs conseguem envolver uma grande quantidade de pessoas, conciliando variadas atividades educativas com os processos de trabalho próprios à EPS e possibilitando a troca de saberes e experiências em diferentes formatos (Silva, Santos, Cortez \& Cordeiro, 2015). 
Nascimento, Kodjaoglanian, De Carli, Loureiro e Moraes (2017) abordaram em seu estudo a formação de tutores por meio da EAD para que estes realizem cursos de especialização a trabalhadores da atenção básica, fruto de um projeto da Universidade Aberta do SUS (UNA-SUS). A capacitação ocorreu pela plataforma AVA Moodlee de modo intercalado com quatro encontros presenciais, proporcionando contato diário com orientadores, debates entre alunos e trocas de experiências do processo de tutoria. Segundo os autores, o programa possibilitou o contato de pessoas de diferentes áreas profissionais, a realização de estratégias formativas de EPS, a criação de um banco de tutores para cursos de especialização, o viés críticoreflexivo e o aperfeiçoamento de discussões pedagógicas importantes para melhoria do projeto.

Para além, Cardarelli e Haddad (2016) demonstraram a utilização da telesaúde, por meio da teleodontologia, na formação e suporte à prática profissional do odontólogo. Tal ferramenta foi estruturada com o auxílio das TICs, possibilitando a troca de informações a respeito de métodos preventivos, diagnósticos e terapêuticas usadas na assistência à população. Os autores relataram que a estratégia ainda propicia melhora no acesso à saúde por comunidades distantes e fragilizadas, utilizando-se da teleeducação interativa e de teleconsultas com especialistas, assim como o compartilhamento de dúvidas e troca de informações entre profissionais por meio da teleconsultoria, além de oportunizar novas possibilidades de EPS, da clínica interdisciplinar e da interação com a comunidade acadêmica.

No que concerne ao uso de recursos audiovisuais, Bacich e Morán (2015) afirmam sua potência para motivar, explicar e ilustrar assuntos a serem trabalhados em diferentes momentos das ações educativas. Santos, Dias e Alves (2019) abordaram o uso desses meios para a capacitação de ACSs na aprendizagem de intervenções em situações de pré-desastres naturais no território adstrito. Na experiência de Azevedo e Gomes (2019), o filme foi utilizado como estratégia de sensibilização sobre a importância das relações interpessoais e atividades em grupo durante uma capacitação de tutores para a EPS. De-Carli, Silva, Zafalon, Mitre, Pereira, Bonfim e Theobald (2019) relataram, ainda, o uso da música como apoio lúdico para a apresentação em seminário final de uma disciplina.

Morán (2015) sustenta a argumentação sobre a necessidade de repensar estratégias formativas de acordo com era cibernética em que estamos inseridos. No atual contexto pandêmico de Covid-19, observa-se que as lacunas entre as atividades educativas presenciais e remotas podem ser minimizadas com a utilização das TICs conectadas à internet. $\mathrm{O}$ isolamento físico desafia gestores, educadores, pais e discentes na mudança do pensar e se fazer educação e saúde, visto que é possível a identificação de abismos entre a população na detenção, acesso e habilidades em relação aos aparatos tecnológicos. As disparidades socioeconômicas e de competências contribui, ainda, para que as estratégias pedagógicas e curriculares da educação híbrida ou à distância desenvolvam alternativas singulares e flexíveis frente às diferentes realidades de vida dos educadores e aprendizes (Camacho, Joaquim, Menezes \& Sant’ Anna, 2020; Sobrinho, Araújo \& Neves, 2020).

\section{Considerações Finais}

Em virtude do que foi exposto, a EPS se apresenta não apenas como um método didático-pedagógico de aprendizagem no ambiente do trabalho, mas como uma decisão política voltada a construir e produzir conhecimento teóricoprático socialmente engajado, que envolva de maneira parceira estudantes, docentes, trabalhadores, gestores do SUS e comunidade para a especialização indissociável do cuidado e da formação em saúde. Trata-se de uma estratégia que visa romper com os paradigmas tradicionais e tecnicistas do processo de ensino-aprendizagem em saúde, objetivando a interação ensino-serviço-comunidade em um viés problematizador, coletivo e interdisciplinar.

Ressalta-se, ainda, a importância da Política Nacional de Educação Permanente em Saúde para a formação de recursos humanos para o SUS e para a consolidação de práticas educativas que promovam aprendizagem significativa e crítica por meio do uso das MAs. Os princípios dessa metodologia corroboram e confluem com os preceitos da EPS ao divergirem do modelo tradicional de ensino e proporem uma educação centrada no aprendiz, no processo de ensino-aprendizagem, no docente como 
mediador e na construção ativa do conhecimento.

Nesse panorama, o presente estudo buscou aprofundar e sistematizar conhecimentos sobre a utilização de estratégias de MAs em processos de EPS, procurando precisar, inicialmente, o conceito de metodologias ativas presentes nos materiais estudados. Ainda, foram apresentadas as diferentes estratégias de ensino pautadas em MAs abordadas, procurando, também, contribuir com algumas reflexões sobre estratégias avaliativas.

Discussões e experiências transformadoras da estrutura de cursos que se utilizaram a MAs puderam ser expostas, ressaltando a vinculação intrínseca entre tais propostas e processos de Educação Permanente em Saúde. Finalmente, apresentou-se o desafio da utilização das TICs e da EAD em face às MAs e os processos de EPS.

Por último, recomenda-se a realização de futuras pesquisas que abordem com maior precisão o conceito acerca das MAs, visando elucidar estratégias de aprendizagem inovadoras e criativas que sejam aplicáveis, replicáveis e transformadoras da realidade.

\section{Referências}

Azevedo, C. R. F. de, \& Gomes, R. (2019). O uso da narrativa na educação permanente em Saúde: sentidos, êxitos e limites educacionais. Interface Comunicação, Saúde, Educação, 23. https://doi.org/10.1590/interface.170957

Bacich, L., \& Moran, J. (2015). Aprender e ensinar com foco na educação híbrida. Revista Pátio, 17(25), 45-47.

Bacich, L., \& Moran, J. (2018). Metodologias ativas para uma educação inovadora: uma abordagem teórico-prática. Penso Editora.

Berbel, N. A. N. (2011). As metodologias ativas e a promoção da autonomia de estudantes. Semina: Ciências Sociais e Humanas, $32(1)$, 25. https://doi.org/10.5433/1679-0383.2011v32n1p25

Bordenave, J. D., \& Pereira, A. M. (2004). Estratégias de ensino-aprendizagem. (26a ed.), Vozes.

Botelho, L. L. R., Cunha, C. C. de A., \& Macedo, M. (2011). O Método Da Revisão Integrativa Nos Estudos Organizacionais. Gestão e Sociedade, 5(11), 121. https://doi.org/10.21171/ges.v5i11.1220

Caldarelli, P. G., \& Haddad, A. E. (2016). Teleodontologia em consonância com as Diretrizes Curriculares Nacionais no desenvolvimento de competências profissionais. Revista da ABENO, 16(2), 25-32.

Camacho, A. C. L. F., Joaquim, F. L., Menezes, H. F. de, \& Sant' Anna, R. M. (2020). A tutoria na educação à distância em tempos de COVID-19: orientações relevantes. Research, Society and Development, 9(5), e30953151. https://doi.org/10.33448/rsd-v9i5.3151

Camurça, A. J. dos S., Dantas, L. P., Rodrigues, F. F. G., Teixeira, M. M. de S., \& Caldas, G. F. R. (2020). O Processo De Ensino E Aprendizagem Em Sala De Aula Como Prática Pedagógica Através Do Team Based Learning - TBL / The Teaching And Learning Process In The Classroom As A Pedagogical Practice Through Team-Based Learning - TBL. Brazilian Journal of Development, 6(9), 66099-66110. https://doi.org/10.34117/bjdv6n9-152

Castro, A. A., Saconato, H., Guidugli, F., \& Clark, O. A. C. (2002). Curso de revisão sistemática e metanálise [texto na Internet]. São Paulo: LEDDIS/UNIFESP, 52-11.

Ceccim, R. B., \& Ferla, A. A. (2008). Educação e saúde: ensino e cidadania como travessia de fronteiras. Trabalho, Educação e Saúde, 6(3), 443-456. https://doi.org/10.1590/S1981-77462008000300003

Conceição, C. V. da, \& Moraes, M. A. A. de. (2018). Aprendizagem Cooperativa e a Formação do Médico Inserido em Metodologias Ativas: um Olhar de Estudantes e Docentes. Revista Brasileira de Educação Médica, 42(4), 115-122. https://doi.org/10.1590/1981-52712015v42n4rb20180013

Cotta, R. M. M., Reis, R. S., Campos, A. A. de O., Gomes, A. P., Antonio, V. E., \& Siqueira-Batista, R. (2013). Debates atuais em humanização e saúde: quem somos nós? Ciência \& Saúde Coletiva, 18(1), 171-179. https://doi.org/10.1590/S1413-81232013000100018

Custódio, J. B., Peixoto, M. das G. B., Arruda, C. A. M., Vieira, D. V. F., Sousa, M. do S. de, \& Ávila, M. M. M. (2019). Desafios Associados à Formação do Médico em Saúde Coletiva no Curso de Medicina de uma Universidade Pública do Ceará. Revista Brasileira de Educação Médica, 43(2), 114-121. https://doi.org/10.1590/1981-52712015v43n2rb20180118

Daltro, M. R., \& Pondé, M. P. (2016). Psychology as a health profession: report of a process of curriculum (re) formulation. Revista Psicologia Da Educação, (42). https://doi.org/10.5935/2175-3520.20150027

Davini, M. C. (2008). Didáctica general para maestros y profesores. Santillana.

De-Carli, A. D., Silva, A. D. da M., Zafalon, E. J., Mitre, S. M., Pereira, P. Z., Bomfim, R. A., Theobald, M. R. (2019). Integração ensino-serviçocomunidade, metodologias ativas e Sistema Único de Saúde: percepções de estudantes de Odontologia. Cadernos Saúde Coletiva, 27(4), 476-483. https://doi.org/10.1590/1414-462x201900040452

Diesel, A., Baldez, A., \& Martins, S. (2017). Os princípios das metodologias ativas de ensino: uma abordagem teórica. Revista Thema, 14(1), 268-288. https://doi.org/10.15536/thema.14.2017.268-288.404 
Fernandes, M. A., Soares, N. S. A., Ribeiro, Í. A. P., Sousa, C. D. C. M., \& Ribeiro, H. K. P. (2018). Metodologias ativas como instrumento para a capacitação em saúde mental. Revista de Enfermagem UFPE on Line, 12(12), 3172. https://doi.org/10.5205/1981-8963-v12i12a237762p3172-3180-2018

Ferreira, J., Celuppi, I. C., Baseggio, L., Savi Geremia, D., Larentes, G. F., \& Hilleshein, A. C. (2018). Managers' training as a strategy for strengthening regionalization of health. Revista de Enfermagem UFPE on Line, 12(4), 1179. https://doi.org/10.5205/1981-8963-v12i4a231285p1179-1184-2018

Fonseca, G. S. (2015). Formação pela experiência: Revelando novas faces e rompendo os disfarces da odontologia\'in vitrol'(Tese de doutorado, Universidade de São Paulo).

França, T., Pierantoni, C., Belisario, S., Medeiros, K., Castro, J., Cardoso, I., \& Garcia, A. (2016). A capilaridade da Política Nacional de Educação Permanente em Saúde no Brasil. CIAIQ2016, 2.

Freire, P. (2015). Pedagogia do Oprimido. (59a ed.), Paz \& Terra.

Freitas, C. M., Freitas, C. A. S. L., Parente, J. R. F., Vasconcelos, M. I. O., Lima, G. K., Mesquita, K. O. de, \& Mendes, J. D. R. (2015). Uso De Metodologias Ativas De Aprendizagem Para A Educação Na Saúde: Análise Da Produção Científica. Trabalho, Educação e Saúde, 13(2), 117-130. https://doi.org/10.1590/1981-7746-sip00081

Gigante, R. L., \& Campos, G. W. de S. (2016). Política de formação e educação permanente em saúde no brasil: bases legais e referências teóricas. Trabalho, Educação e Saúde, 14(3), 747-763. https://doi.org/10.1590/1981-7746-sip00124

Gil, C. (1994). Métodos e técnicas de pesquisa social: um tratamento conceitual. Atlas.

Gomes, L. B., Barbosa, M. G., \& Ferla, A. A. (2016). A Educação Permanente em Saúde e as redes colaborativas: conexões para a produção de saberes e práticas. Editora Rede Unida.

Gonçalves, C. B., Pinto, I. C. de M., França, T., \& Teixeira, C. F. (2019). A retomada do processo de implementação da Política Nacional de Educação Permanente em Saúde no Brasil. Saúde Em Debate, 43(spe1), 12-23. https://doi.org/10.1590/0103-11042019s101

Governo Federal (BR). (1990). Lei № 8.080, de 19 de setembro de 1990. Dispõe sobre as condições para a promoção, proteção e recuperação da saúde, a organização e o funcionamento dos serviços correspondentes e dá outras providências.

Guimarães, I. F., \& Corvino, M. P. F. (2016). Estratégias de educação permanente em saúde na percepção dos profissionais de Vigilância Sanitária. Vigilância Sanitária Em Debate, 4(1), 58. https://doi.org/10.3395/2317-269x.00477

Hartz, A. M., \& Schlatter, G. V. (2016). A Construção Do Trabalho De Conclusão Do Curso Por Meio Da Metodologia Ativa Team-Based Learning. Administração: Ensino e Pesquisa, 17(1), 73-109. https://doi.org/10.13058/raep.2016.v17n1.274

Hermida, P. M. V., Barbosa, S. S., \& Heidemann, I. T. S. B. (2015). Metodologia ativa de ensino na formação do enfermeiro: inovação na atenção básica. Revista de Enfermagem Da UFSM, 5(4). https://doi.org/10.5902/2179769216920

Lázaro, A. C., Sato, M. A. V., \& Tezani, T. C. R. (2018). Metodologias ativas no ensino superior: o papel do docente no ensino presencial. São Carlos, SP: CIET: EnPED.

Lemos, C. L. S. (2016). Educação Permanente em Saúde no Brasil: Educação ou gerenciamento permanente? Ciência e Saúde Coletiva, 21(3), 913-22. DOI: $10.1590 / 1413-81232015213.08182015$

Lopes, M. T. S. R., Labegalini, C. M. G., \& Baldissera, V. D. A. (2017). Educar para humanizar: o papel transformador da educação permanente na humanização da atenção básica [Educating to humanize: the transformer role of permanent education in the primary care humanization] [Educar para humanizar: el papel transformador de la. Revista Enfermagem UERJ, 25, e26278. https://doi.org/10.12957/reuerj.2017.26278

Luckesi, C. (2014). Sobre notas escolares: distorções e possibilidades. Cortez.

Luckesi, C. (2018). Avaliação em educação: Questões epistemológicas e práticas [evaluation in education: Epistemological and practical questions]. Cortez.

Ministério da Saúde (BR). (2017). Portaria nº 2, de 28 de setembro de 2017. Consolidação das normas sobre as políticas nacionais de saúde do Sistema Único de Saúde. Diário Oficial da União. Brasília, DF, 2017.

Ministério da Saúde (BR). (2004). Portaria. MS nº 198, de 13 de fevereiro de 2004. Institui a Política Nacional de Educação Permanente em Saúde como estratégia do Sistema Único de Saúde para a formação e o desenvolvimento de trabalhadores para o setor dá outras providências. Diário Oficial da União. Poder Executivo, Brasília, DF, 16.

Ministério da Saúde (BR). (2014). Portaria nº 278, de 27 de fevereiro de 2014. Institui diretrizes para implementação da Política de Educação Permanente em Saúde, no âmbito do Ministério da Saúde (MS). Diário Oficial da União. Poder Executivo, Brasília, DF, 27.

Ministério da Saúde (BR). (2018). Política Nacional de Educação Permanente em Saúde: o que se tem produzido para o seu desenvolvimento? Brasília: Ministério da Saúde.

Moran, J. (2015). Mudando a educação com metodologias ativas. In: Souza C A, Morales OET (organizadores). In Coleção Mídias Contemporâneas. Convergências Midiáticas, Educação e Cidadania: aproximações jovens.

Nascimento, D. D. G. D., Kodjaoglanian, V. L., De Carli, A. D., Loureiro, M. D. R., \& Moraes, S. H. M. D. (2017). A educação permanente como estratégia formativa para tutores em educação a distância: a experiência da UNA-SUS Mato Grosso do Sul. Experiências exitosas da Rede UNA-SUS: trajetórias de fortalecimento e consolidação da Educação Permanente em Saúde no Brasil. EDUFMA. 
Noro, L. (2019). Como Estruturar Um Currículo Integrado Num Curso De Odontologia? Revista Ciência Plural, 5(1), 1-17. https://doi.org/10.21680/24467286.2019v5n1ID17942

Pinheiro, G. E. W., Azambuja, M. S. de, \& Bonamigo, A. W. (2018). Facilidades e dificuldades vivenciadas na Educação Permanente em Saúde, na Estratégia Saúde da Família. Saúde Em Debate, 42(spe4), 187-197. https://doi.org/10.1590/0103-11042018s415

Pischetola, M., \& Miranda, L. T. de. (2019). Metodologias ativas, uma solução simples para um problema complexo. Educação e Cultura Contemporânea, 16(43). https://doi.org/10.5935/2238-1279.20190003

Rabelo, L., \& Garcia, V. L. (2015). Role-Play para o Desenvolvimento de Habilidades de Comunicação e Relacionais. Revista Brasileira de Educação Médica, 39(4), 586-596. https://doi.org/10.1590/1981-52712015v39n4e01052014

Santos, A. L., \& Rigotto, R. M. (2010). Território e territorialização: incorporando as relações produção, trabalho, ambiente e saúde na atenção básica à saúde. Trabalho, Educação e Saúde, 8(3), 387-406. https://doi.org/10.1590/S1981-77462010000300003

Santos, L. (2016). A articulação entre a avaliação somativa e a formativa, na prática pedagógica: uma impossibilidade ou um desafio? Ensaio: Avaliação e Políticas Públicas Em Educação, 24(92), 637-669. https://doi.org/10.1590/S0104-40362016000300006

Santos, P. Z. dos, Dias, J. I., \& Alves, R. B. (2019). Educação permanente sobre a atenção psicossocial em situação de desastres para agentes comunitários de saúde: um relato de experiência. Saúde Em Debate, 43(spe3), 200-208. https://doi.org/10.1590/0103-11042019s315

Schultz, T. W. (1985). O valor econômico da educação. Zahar.

Silva, A. das N., Santos, A. M. G. dos, Cortez, E. A., \& Cordeiro, B. C. (2015). Limites e possibilidades do ensino à distância (EaD) na educação permanente em saúde: revisão integrativa. Ciência \& Saúde Coletiva, 20(4), 1099-1107. https://doi.org/10.1590/1413-81232015204.17832013

Simão, A. L., Teixeira, A. É. E. A., Freitas, R. N. D., Viana, B. M. M. R., \& Pinheiro, F. E. D. S. (2016). Uso do diário de campo em pesquisa científica: relato de experiência. Encontros Universitários da UFC, Fortaleza, v. 1.

Sobrinho, R. A., Araújo, J. de A., \& Neves, B. C. (2020). Covid-19, Tecnologia Digital e Educação. Folha de Rosto, 6(2), 70-82. https://doi.org/10.46902/2020n2p70-82

Souza, R. M. P., \& Costa, P. P. (2019). Educação Permanente em Saúde na formação da Rede Brasileira de Escolas de Saúde Pública. Saúde Em Debate, 43(spe1), 116-126. https://doi.org/10.1590/0103-11042019s110

Torres, P. L., Alcantara, P. R., \& Irala, E. A. F. (2004). Grupos de consenso: uma proposta de aprendizagem colaborativa para o processo de ensinoaprendizagem. Diálogo Educacional.

Valente, J. A., Bianconcini de Almeida, M. E., \& Flogi Serpa Geraldini, A. (2017). Metodologias ativas: das concepções às práticas em distintos níveis de ensino. Revista Diálogo Educacional, 17(52), 455. https://doi.org/10.7213/1981-416X.17.052.DS07

Vasconcelos, M. I. O., Farias, Q. L. T., Nascimento, F. G., Cavalcante, A. S. P., Mira, Q. L. M., \& Queiroz, M. V. O. (2017). Educação Em Saúde Na Atenção Básica: Uma Análise Das Ações Com Hipertensos. Revista de APS, 20(2). https://doi.org/10.34019/1809-8363.2017.v20.15943

Whittemore, R., \& Knafl, K. (2005). The integrative review: updated methodology. Journal of Advanced Nursing, 52(5), 546-553. https://doi.org/10.1111/j.1365-2648.2005.03621.x 